\title{
Optoelectronic technology profiles: motivating and developing research skills in undergraduate students
}

D. Kane

D. M. Kane, "Optoelectronic technology profiles: motivating and developing research skills in undergraduate students," Proc. SPIE 9666, 11th Education and Training in Optics and Photonics Conference, 96661H (5 June 2009); doi: $10.1117 / 12.2207978$

Event: Eleventh International Topical Meeting on Education and Training in Optics and Photonics, 2009, St. Asaph, United Kingdom 


\title{
Optoelectronic Technology Profiles - Motivating \& Developing Research Skills in Undergraduate Students
}

\author{
D M Kane \\ Department of Physics, Macquarie University Sydney, NSW 2109, Australia \\ Email: debkane@science.mq.edu.au
}

\begin{abstract}
A case study is described of the redesign of an assessment task - the writing of an Optoelectronic Technology profile - to achieve improved outcomes in student education and capability development, in particular, research skills. Attention is drawn to the value of a formally scheduled discussion between teacher and student around controlling the scope of the profile via an appropriately constructed "brief", and the selection and evaluation of the reference resources to be used in completing the task. Student motivation is improved through "student publishing" and encouraging students to regard their technology profile as an example of their work that can be shown to potential employers, possibly as part of a portfolio. Students have the choice as to whether they will also use the technology profile task as a vehicle to develop teamwork experience and skills.
\end{abstract}

\section{INTRODUCTION}

Macquarie University introduced a three year Bachelor of Technology (Optoelectronics) degree as one of a program of BTech degrees in 1990. The first cohort of students completed the degree in 1992. The graduates of this degree were targeted to employment in the emerging photonics industries of Australia. Thus, components of the degree (and its successor phased in from 2007) have to address development of skills and capabilities in several key areas such as: knowledge and understanding of appropriate content; problem solving skills; comfort and confidence with sophisticated photonics and optics related instrumentation; communication skills; time management; and research skills. One key assessment task to develop the latter three skills requires the students to research and write a Technology Profile, on an area of optoelectronic/photonic technology of their choice, most often from a comprehensive list provided. This was one of the assessment tasks in the unit of study "Optoelectronic Systems and Devices II", a third year, second semester unit. They also gave a seminar to the class and teaching staff, drawn from the content of their Technology Profile. After almost ten years of this offering, teaching staff noted that the engagement by students with this assessment task, was waning. Also, the quality of the technology profiles submitted was perceived as diminishing and there was an increase in use of "cut-and-paste". These changes were not judged as being correlated with any identifiable change in the ability or background of the student cohort at that time. Instead it was concluded that a process of renewal of the task should be undertaken with the aim of increasing student motivation, increasing student engagement and learning, decreasing plagiarism, increasing the priority student's gave to completing the task, and increasing the real and perceived benefits by the students. These learning dimensions are summarised in Table 1. To assist the students to develop the necessary research skills they are given an example of an Optoelectronic Technology Profile written by the author, along with a "how to/ where to" find the information that will be needed for different types of technology profile. Examples are reviews of a mature technology, or a state-of-play of an emerging technology. Students are assisted to use their "brief" as a tool to manage the reference set that needs to be assimilated and synthesised to adequately address their chosen topic. They learn about time and project management, as well as the technology, via this task design. 


\begin{tabular}{|l|}
\hline \multicolumn{1}{c|}{ Learning Dimension } \\
\hline Student motivation - to be increased \\
\hline Student engagement and learning - to be increased \\
\hline Research skills - to be developed \\
- $\quad$ Original authorship \\
- $\quad$ Quality Writing \\
- $\quad$ Creativity - the brief, creative communication \\
- $\quad$ Critical evaluation of reference sources - print and on-line \\
- $\quad$ Planning an optimum format for a report \\
- $\quad$ Pelection and creation of visual materials \\
- $\quad$ Writing to later reformat for presentation \\
- $\quad$ Planning \\
- $\quad$ Efficient and productive use of time \\
\hline Plagiarism - to be decreased \\
\hline Increase the real and perceived benefits gained by students \\
\hline
\end{tabular}

Table 1: Summary of planned learning outcomes and skill and capability development.

Student motivation is also addressed by "publishing" an annual volume of the technology profiles from the class as a whole and this has been a successful motivator for most students. Students are encouraged to produce an example of their work that they can show to potential employers. This student publishing was one of the features of teaching practice in the department that was selected for inclusion in the resource booklet from the project "learning outcomes and curriculum development in physics" produced as a national resource for tertiary physics teaching and learning in Australia ${ }^{1}$. Plagiarism is still an issue for a small number of students and some technology profiles are not "published" for this and other reasons. The importance of the dialogue between the "teacher" and each student as an individual, around the task, emerges as a key driver of deeper learning. Motivating students to complete the planning stages of the task in good time, so they may avoid making poor decisions on topic, and reference resource selection, with inadequate time to complete the task to the best of their abilities, remains a challenge. Student engagement, and therefore benefits, remains variable across the student population. A major benefit of the explicit and detailed nature of the task design is that it facilitates the teacher to have an evidence based discussion with individual students on how they could readily improve by planning and increased engagement.
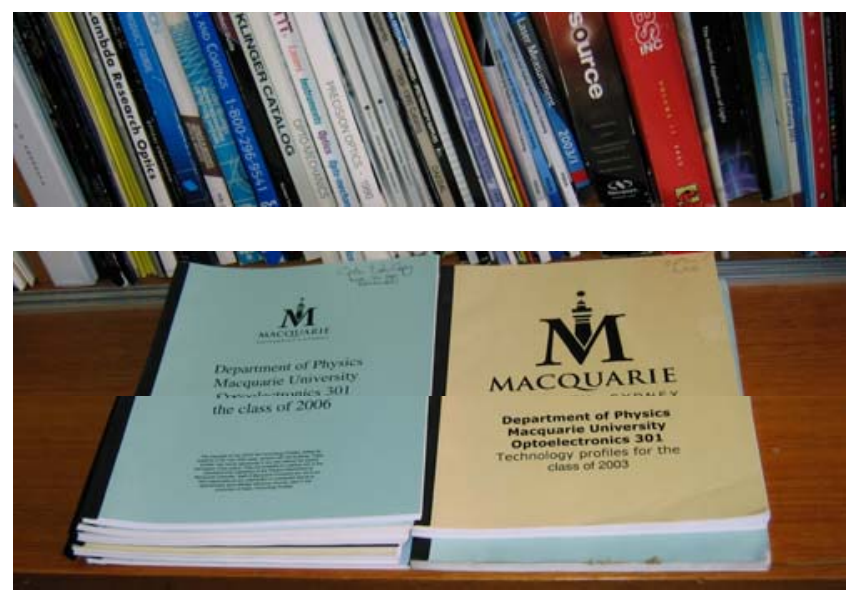

Fig. 1 Optoelectronics technology profile volumes as distributed to each student in the class. Profiles are copyright of the individual students and permission must be sought from the student for profiles to be distributed outside the class. 


\section{THE OPTOELECTRONIC TECHNOLOGY PROFILE TASK}

The description of the Technology Profile (TP) task that is distributed to students is given in Appendix A. The task is divided into three main components - (i) the development of a "brief", and the selection and evaluation of an appropriate set of reference materials; (ii) the completion of the technology profile, informed by the discussion of, and appropriate modification of (i); and (iii) producing a twenty minute presentation from the technology profile. A range of educational resources are available to support student learning in the various parts of the task and these are referenced below. Advice on development of the "brief" and accessing reference resources is also illustrated to the students in the context of an example TP distributed to students. This advice is reproduced in Appendix B. A PERT diagram of the skills and capabilities to be developed, and the elements of the task that support them, is shown in Fig. 2. To support the prime focus on developing research skills, this figure should also be interpreted to students to note the link between good time management and good communication skills as necessary partners to good research skills. It is possible to present all these skills as research skills.

\begin{tabular}{|c|c|c|}
\hline Skills & \multicolumn{2}{|c|}{ OPTOELECTRONIC TECHNOLOGY PROFILE ASSESSMENT TASK } \\
\hline \multicolumn{3}{|l|}{ Research Skills } \\
\hline \multirow{2}{*}{\multicolumn{3}{|c|}{ Communication }} \\
\hline & & \\
\hline \multicolumn{3}{|l|}{ Time Management } \\
\hline \multirow{3}{*}{$\begin{array}{l}\text { How long should you } \\
\text { assign to this task? } \\
\text { How is this time to } \\
\text { be divided between } \\
\text { the components of } \\
\text { the task? }\end{array}$} & $\begin{array}{l}\text { Discussion with team members to agree } \\
\text { topic and context (the "brief") }\end{array}$ & \\
\hline & $\begin{array}{l}\text { Discussion with team members to } \\
\text { assign research and writing packages }\end{array}$ & \\
\hline & $\begin{array}{l}\text { Discussion with team members to review } \\
\text { reference materials and resources }\end{array}$ & \\
\hline \multirow{2}{*}{$\begin{array}{l} \\
\text { Develop the Brief, } \\
\text { Source Reference } \\
\text { Material }\end{array}$} & & \multirow{2}{*}{$\begin{array}{l}\text { Select and Evaluate } \\
\text { Reference Resources }\end{array}$} \\
\hline & $\begin{array}{l}\text { Discussion with lecturer to finalise brief } \\
\text { and the reference resources }\end{array}$ & \\
\hline \multirow{2}{*}{$\begin{array}{l}\text { Plan, Draft, and } \\
\text { Write Technology } \\
\text { Profile }\end{array}$} & $\begin{array}{l}\text { Produce high quality Technical/ Scientific } \\
\text { writing conforming to an appropriate } \\
\text { professional format }\end{array}$ & $\begin{array}{l}\text { Select and Specify an } \\
\text { appropriate professional } \\
\text { format for the TP }\end{array}$ \\
\hline & Plan ahead for multi-media communication & \multirow{2}{*}{$\begin{array}{l}\text { Develop Understanding } \\
\text { of, and capability at } \\
\text { content management }\end{array}$} \\
\hline & $\begin{array}{l}\text { - a powerpoint-based presentation will be } \\
\text { prepared from the TP }\end{array}$ & \\
\hline & Get feedback on your writing and act on it & \multirow{2}{*}{$\begin{array}{l}\text { Develop Knowledge and } \\
\text { Understanding of the } \\
\text { Reference Materials }\end{array}$} \\
\hline & $\begin{array}{l}\text { Feedback and discussion between team } \\
\text { members to achieve a consistent and }\end{array}$ & \\
\hline \multirow{2}{*}{$\begin{array}{l}\text { Submit Completed } \\
\text { Technology Profile }\end{array}$} & $\begin{array}{l}\text { coherent style and treatment throughout } \\
\text { the whole of the technology profile }\end{array}$ & \multirow{2}{*}{$\begin{array}{l}\text { Select and/or develop } \\
\text { Visuals / Graphs / Tables } \\
\text { for Inclusion in TP (and } \\
\text { presentation) }\end{array}$} \\
\hline & $\begin{array}{l}\text { Ensure any feedback on the assessed TP is } \\
\text { fully understood. Respond to it in the } \\
\text { presentation }\end{array}$ & \\
\hline $\begin{array}{l}\text { Produce Powerpoint } \\
\text { Presentation } \\
\text { (Including } \\
\text { Responding to } \\
\text { Feedback on TP) }\end{array}$ & $\begin{array}{l}\text { Reflect on what has been learned. } \\
\text { Document and save useful resources } \\
\text { for future use. Archive TP and } \\
\text { presentation. Submit corrected TP for } \\
\text { class publication. }\end{array}$ & $\begin{array}{l}\text { Grey font - relevant to teams } \\
\text { Black font - relevant to all } \\
\end{array}$ \\
\hline
\end{tabular}

Fig. 2 PERT diagram of the components of the task, the skills to be educated and developed, and the links and relationships between them. Sub-tasks and the sub-skills appear chronologically down the time management and communication columns of the diagram and correlate across the diagram. 
The students completing this task have had extensive experience with writing laboratory reports on experiments they have completed - for all of three hour, six hour, and nine hour experiments across optoelectronics, optics, and physics. Their laboratory report writing skills are well developed and the consensus guideline used by all students in the department is informed by research into processes for improving student writing $^{2}$. They have also completed assessment tasks involving familiarisation with optoelectronic device and system specification sheets and application notes. In this task they are building on this experience and capability to write the technology profile. Accessing standard educational support materials on evaluation of reference resources ${ }^{3-8}$ and report writing ${ }^{8-11}$ does facilitate completing the task. However, it is also important to inform the students of the need to include reference resources such as product information and patents that are not highlighted in many of the standard guidelines for "How to do library-based research".

It is the discussion of the task that occurs, between teacher and students, that is the vehicle by which students learn a number of important points:

(i) How the type and quality of the reference resources used will, in large part, determine the quality of the technology profile.

(ii) How the type of reference resources that are best suited changes with the nature of the "brief".

(iii) The importance of time and content management when completing the task is to be matched to a finite time available.

They are encouraged to assign a specific time allocation to completing the technology profile - say 25 hours. They then learn there is limited benefit in spending a large amount of the available time accessing more reference material than they can subsequently assimilate, compare and contrast. Student awareness of how the quantity of material that needs to be accessed and assimilated scales with the breadth of the technology area to be addressed, is raised. If the topic is to be a review of a broad technology area the students learn it will be very difficult to produce a high quality technology profile that is an excellent synthesis of the field without high quality review resources to use as references. The students have their awareness raised of the causal links between the scale of the task, an appropriate set of high quality reference materials that will be needed to complete the task to an excellent standard, and the time it will take to follow this through the various research stages to completion. The students are empowered to plan for an excellent technology profile through their control of the brief. They can scale the task to achieve an excellent technology profile in the time they assign. The task supports the student to gain self knowledge of their own capability, and, work rate and ethic. The lecturer can also provide feedback to the student on these issues as part of the discussion.

\section{Uptake by Teams}

Few students elect the option of completing a larger scale TP by a team. Four is the largest number of students who have cooperated on the task and pairs are the most common multiple submission. Despite the identification of the additional skills, that are highly valued by potential employers (grey-font text boxes in figure 1), that come from teamwork, students mostly pursue the task individually, on workload grounds. The assignment of a single grade to all members of a team, and the loss of an opportunity to produce an individual portfolio work sample are also disincentives to some students. However, the design of the task raises student awareness of the additional communication requirements brought by working in a team and the necessity of deploying a team to achieve a major report in a prescribed time. Students do engage more frequently, as a team, on smaller scale assessment tasks such as group assignments. However, compulsory teamwork would ensure students do gain teamwork experience. Formal contact hours for team meetings would then need to be assigned to the task.

\section{DISCUSSION \& CONCLUSIONS}

The technology profile learning task has been designed to address specific learning dimensions as listed in Table 1. Evaluation of the success of the TP in achieving the planned improvements is based on student feedback and the reflections of the teacher as 'practitioner'. They are not research based. The small student numbers in the class prevent a statistically significant result of a controlled study from being achieved in the specific case described. However, the purposeful engagement by students in the discussion of their 
technology profile brief and the selection and evaluation of appropriate reference materials to use, and their subsequent modified briefs and reference sets, have been clear indicators of improved learning outcomes. Given the clear learning advantages identified it would be difficult to justify carrying out a controlled study, where similar GPA distribution groups are compared, one group denied the discussion step in the process in order to measure quantitatively the difference it makes in final assessment. The learning opportunity would be significantly reduced for the control group. The research skills of the teacher-as-guide are also important for the successful implementation of such learning tasks. The teaching staff are required to have active and current high level research skills. The planned inclusion of such learning tasks in the curriculum is one argument for the need to maintain highly skilled teaching-and-research staff in university departments. At a time when research skills are being identified as needing to be included explicitly in undergraduate curricula, at an increased proportion, any trend towards increased specialisation and separation of research and teaching in staff demographics will reduce the positive learning outcomes that can be expected in developing research skills in the graduates.

\section{APPENDIX A - DESCRIPTION OF THE TASK (EDITED)}

\section{Technology Profiles}

A technology profile on an optoelectronics device or system is due on "Date". A list of suggested topics is supplied. The technology profile by an individual should be about 3000 words in length with appropriate use of figures and diagrams. You have the option to complete the technology profile as a team task with proportional scaling of the length. This would enable a profile covering a small technology area in great detail, or discussion of a related series of technologies, or a broader technology to be covered in detail, in addition to gaining teamwork skills. Most workplaces are structured around teams of people rather than individuals. The profile will be preceded by handing in a brief and a list/file of reference material to be used for the profile by "Date $\mathbf{- 1}$ month".

We will provide all students in the class with a bound copy of the profiles, subject to an appropriate level of quality being achieved. A copy of the profiles will also be included in the Optoelectronics Laboratory library. We hope that these profiles will be useful for you in your future careers, and you may wish to show your profile to potential employers to indicate your abilities.

\section{What is required?}

You should begin by determining your brief and the reference sources to be used in producing the technology profile. For example, imagine that you are a technology consultant, asked to summarise the current state of a particular optoelectronic technology (system or device) for a company that is considering using the technology. Your brief would be to understand how the system or device works, to analyse the advantages and limitations of the technology either generally, and/or for the specific purpose envisaged, and possibly to compare and contrast the technology with the one currently being employed. Selection of reference resources is critical to completing a high quality technology profile.

You must submit your brief and list of/file of references to be used, and the members of your team if applicable, on or before "Date - 1 month".

The profile should first state the brief, and provide an executive summary of no more than 250 words of your conclusions with respect to your brief. The body of the text should explain the physical phenomena underlying the technology that you select, and discuss typical designs, specifications, parameters or operating conditions. You should aim to provide an up-to-date survey of the topic, and must cite the sources (books, journal articles, patents, web sites and product literature) used for the profile fully. Depending on your topic, you may discuss commercial or fabrication issues associated with the technology. You should aim for a clear, readable style in your profile text. Profiles written by teams should not be simply an assembly of individual efforts, but should have a coherent overall structure. You should only choose the teamwork option 
if you can timetable meeting as a team to plan and coordinate the production of a single, larger-scale technology profile. Building teamwork skills is highly desirable.

\section{Seminars}

Each member of the class will present a 20 minute talk, either as part of a team presentation or as an individual presentation from their technology profile, after "Date $+\mathbf{1}$ week". Additional notes will be given on seminar presentation later in the semester.

Your audience will be both academics and peers, and each member of the audience will provide written comments on the talks. You should aim for clear, persuasive and logical presentation of the concepts and ideas. Enthusiasm and careful preparation are important for good presentations, and we expect you should practice your talk in advance to improve your timing and fluency. Teams should ensure that each member presents a coherent section of the whole.

\section{Topics}

Each individual and team should choose a different topic. This will avoid doubling up on topics in the seminars and bound collection of profiles to be distributed at the end of semester. The topic should be different to your industrial project. Other topics of your own choosing may be acceptable. Please discuss your topic, and subsequently develop your brief in discussion with "The Lecturer" early in the semester.

\begin{tabular}{|c|c|}
\hline Laser applications in chemical or trace gas analysis & Laser material processing \\
\hline Laser applications in diagnostic and therapeutic medicine & Wireless optical communication systems \\
\hline $\begin{array}{l}\text { Fibre optical communications systems- long haul or } \\
\text { metropolitan area networks }\end{array}$ & $\begin{array}{l}\text { Wavelength reference sources for optical } \\
\text { communication systems }\end{array}$ \\
\hline Laser-assisted mass deposition & Dense wavelength division multiplexing \\
\hline Laser marking & Optical data storage \\
\hline Laser welding systems & Optical computing \\
\hline The lasers and optics of lithography systems & Optical switching and signal processing \\
\hline Remote sensing/ LIDAR & Point to point communications \\
\hline Barcode readers & Optical fibre gratings \\
\hline Optically Pumped Semiconductor Lasers & Passive fibre components \\
\hline Industrial holography & Active fibre components \\
\hline Optical coherence tomography & Quantum dot lasers \\
\hline $\begin{array}{l}\text { Identify an application that needs a laser source at a } \\
\text { single, particular wavelength and then research all } \\
\text { possible laser systems that might meet the need. }\end{array}$ & $\begin{array}{l}\text { Optical measurement standards (e.g. time or } \\
\text { frequency standards) }\end{array}$ \\
\hline Laser TV & High speed modulated light sources \\
\hline 3-D displays & Integrated optic modulators \\
\hline LCD or laser displays & Fibre-compatible optical switches \\
\hline Spatial light modulators & Blu-ray Disc \\
\hline Laser scanners & Planar integrated optoelectronics \\
\hline Fibre endoscopes & Photonic crystals \\
\hline Image processing & Photonic band gap materials or holey fibres \\
\hline Confocal microscopy & Polymers in optoelectronics \\
\hline LEDs for Lighting & Optical superprisms \\
\hline Thin film optical coating systems & Radiometry \\
\hline Spectrometers & Thermal or IR viewers \\
\hline Optical wavemeters & Laser beam profilers \\
\hline Optical spectrum analysers & Laser beam quality measurement systems \\
\hline Micro opto-mechanical systems & Photometry \\
\hline Streak cameras & Laser power meters \\
\hline
\end{tabular}




\begin{tabular}{|l|l|}
\hline Nanolithography using photons & Integrating spheres and their applications \\
\hline ZnO as an emerging material for integrated photonics & Silicon optoelectronics \\
\hline Laser ablation for space propulsion & Optical tweezers \\
\hline
\end{tabular}

Students are issued with a detailed breakdown of how the technology profile and seminar are assessed.

\section{APPENDIX B - ADVICE ON DEVELOPMENT OF THE "BRIEF" AND ACCESSING REFERENCE RESOURCES USING AN EXAMPLE TECHNOLOGY PROFILE - "ORGANIC SEMICONDUCTOR LASERS", WRITTEN IN 2001}

\section{The Brief}

A company which uses standard 5-100 mW semiconductor lasers, at wavelengths in the range of $650 \mathrm{~nm}$ to $1.5 \mu \mathrm{m}$, as a light source in a range of spectroscopic analysis equipment, has heard that the first injection laser based on an organic semiconductor was demonstrated and reported in the year 2000. The company engages you as a consultant to prepare a technology profile on organic semiconductor lasers so they may evaluate on what timescale, if ever, organic semiconductor lasers will be a possible alternative laser source for incorporation in their instrumentation. They are also interested to know if there are any identifiable advantages of organic semiconductor lasers over standard semiconductor lasers for their instrumentation.

\section{Finding Appropriate Reference Material}

As the injection organic semiconductor laser has just been demonstrated you know they will not be commercially available and so a search for commercial suppliers on the world wide web is not appropriate. There may well be some patents, however. Also, a normal precursor to demonstrating injection laser operation of semiconductor gain media is to demonstrate LED operation, and possibly laser operation using optical or electron beam excitation. You expect there will be a wealth of research literature on these topics and possibly some commercial suppliers. However, there are likely to be far more research papers than you would care to study and the information in them is likely to be in more detail than you require for your profile. Hence, the best start points for you are to

(i) locate the report(s) of the first injection organic semiconductor laser,

(ii) search for review articles on organic semiconductor LEDS, and lasers excited by means other than injection

(iii) look at websites of the institutions of the authors of any reviews found in (ii),

(iv) identify other key research papers or trade magazine articles from (i), (ii) and (iii) and database searching,

(v) search patent office sites for relevant patents, and,

(vi) search the web for any companies which have, or are about to commercialise organic LEDs or lasers.

A search of the INSPEC database for articles on organic semiconductor lasers published in the year 2000 locates the Science article of Schon et al that has generated the interest ${ }^{*}$. Still using INSPEC, combining a search of the complete database on organic semiconductor lasers and a search on reviews unearths a review published in 1999. This is good luck as a recent review article is a perfect primary source from which to begin your study and from which to source additional secondary sources. Also, having identified the address of someone sufficiently expert in the field to be the author of a review article you can search the www to determine if they have a website which may contain useful information on your topic. This is found to be the case. The Cavendish Laboratory Optoelectronics Group homepage has a report of a research project on LEDFOS (light emitting devices from organic semiconductors) which lists key references and companies active in the research. Careful reading of the review article shows its not actually a high quality reference in terms of coverage and content so its usefulness is more in determining other reference sources. A search of the US Patent Office website (www.uspto.gov) lists 12 patents on organic semiconductor lasers. You browse

* This research was subsequently shown to be fraudulent and key papers were withdrawn from Science. However, the example is still used, but, it is also used to discuss research and professional ethics using the Schon case as an example. 
through these and select one that has information that is relevant to your brief. The LEDFOS project website identifies several companies involved in commercial development of polymer LEDs, predominantly for display applications. You find the Philips company website has some excellent print resources on making polymer LEDs. With this collection of resources you are well placed to complete your technology profile for the company.

In selecting references to prepare the technology profile it is important to select resources you can understand with a reasonable amount of mental effort on your part and to ensure that they are sufficient in number, range and quality to gain an overview of your topic. If a "blowout" in reference material occurs you have the control of the "brief" that can be modified to avoid this blowout.

A copy of the example Optoelectronics Technology Profile - "Organic Semiconductor Lasers" is available upon request by email from Deb Kane

\section{ACKNOWLEDGEMENTS}

It is a pleasure to acknowledge discussions with A/Prof Judith Dawes and A/Prof David Coutts, both staff of the Department of Physics, Macquarie University with whom I have shared lecturing the third year "Optoelectronics Devices and Systems II" unit in which the Optoelectronic Technology Profile is one of the assessment tasks. The list of suggested topics evolves over time with input from all teaching staff.

\section{Copyright (C) 2009 D M Kane}

The author assigns to SPIE and educational non-profit institutions a non-exclusive licence to use this document for personal use and in courses of instruction provided that the article is used in full and this copyright statement is reproduced. The author also grants a non-exclusive license to SPIE to publish this document on the Web (prime sites and mirrors) and in printed form within the ETOP 2009 Conference Proceedings. Any other usage is prohibited without the express permission of the author.

\section{REFERENCES}

[1] Snapshots - Good learning and teaching in physics in Australian Universities, a publication of the Learning outcomes and curriculum development in physics project, p. 24, ISBN: 0732620643 (2005), also [Online] Available: www.physics.usyd.edu.au/super/AUTC/documents/pdf/Booklet.pdf [accessed 2009, 16 June]

[2] Roger, P., Freeman, T., and Kane, D. M. (1999) Laboratory report writing skills for undergraduate Physics students, pp 252-7, in "Language Analysis, Description and Pedagogy", Eds Berry, R., Asker, B., Hyland, K., and Lam, M. (The Hong Kong University of Science and Technology, 1999).

[3] How to do Research, [Online] Available: http://www.lib.mq.edu.au/studyandresearchtools/HowtodoResearch.html [accessed 2009, 16 June] Note: Most university libraries have such a webpage.

[4] What Web Search Engines Won't Find, [Online] Available: http://www3.widener.edu/Academics/Libraries/Wolfgram_Memorial_Library/Need_Help_/How_to_do_Res earch/What_Web_Search_Engines_Won_t_Find_/498/[accessed 2009, 16 June]

[5] J. Alexander and M.A.Tate (1996-2005) How to Recognize an Informational Web Page, [Online] Available:http://www3.widener.edu/Academics/Libraries/Wolfgram_Memorial_Library/Evaluate_Web_Pag es/Checklist_for_an_Information_Web_Page/5720/ [accessed 2009, 16 June]

[6] Evaluating Sources: Overview [Öline] Available: http://owl.english.purdue.edu/owl/resource/553/01/ [accessed 2009, 16 June]

[7] Evaluation of information sources, collated by Alistair Smith, [Online] Available: http://www.vuw.ac.nz/staff/alastair_smith/evaln/evaln.htm [accessed 2009, 16 June]. Part of the "Information Quality WWW Virtual Library" [Online] Available: http://www.ciolek.com/WWWVLInfoQuality.html

[8] Purdue's Online Writing Lab, [Online] Available: http://owl.english.purdue.edu/oldindex.html [accessed 2009, 16 June]. A comprehensive resource covering all aspects of writing.

[9] Handbook of Report Formats [Online] Available: 
http://owl.english.purdue.edu/owl/resource/726/01/ [accessed 2009, 16 June].

[10] D A McMurrey, Power Pools for Technical Communication [Online] Available:

http://www.io.com/ hcexres/power_tools/index.html [accessed 2009, 16 June]

[11] D A McMurrey, Online Technical Writing - Online Textbook [Online] Available: http://www.io.com/ hcexres/textbook/index.html [accessed 2009, 16 June] 